\title{
TRANSPORTES E PLANIFICAÇÃO DO TURISMO
}

\author{
Érico Manoel de Almeida'
}

\begin{abstract}
RESUMO: O estudo do 'lurismo c do Transportc. dado o scu carriter complementar. tem demonstrado fatta de clarcza nos seus respectivos limites. Pouca bibliografia solbrc a matćria iclegá o Turismo a uma posiçăo inferior na escala de prioridades sociais no Brasil. $S$ cm respostas, muito se tem discutido sobre a demanda turística. at ração c geração de viagens. A análise por cixos cartcsianos e o csl udo de iscrustos podc. de maneira clara e objetiva. sugcrir critérios para uma lomada de decisão política, sem que sc csbarre na dificuldade de justificar a cconometria turística.
\end{abstract}

PAL.AVRAS-CHAVE: Turismo: transportc: hotela ria: planificação.

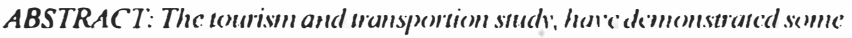

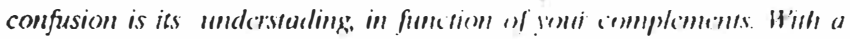

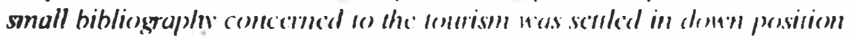

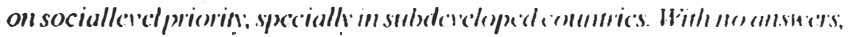

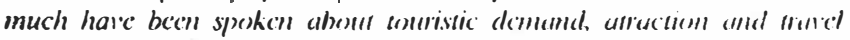

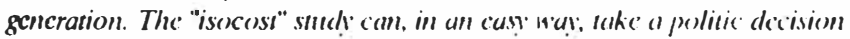

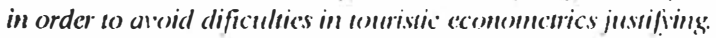

KEYWORDS: Tourism: transp)ort: hotels; plamming.

\section{INTRODUÇÃO}

É possível que o Turismo scja uma "simples marca" do grande desenvolvimento do Transporte, c o entendimento deste processo evolutivo pode explicar o próprio turismo como força cconômica c como fenômeno social. Com poucos estudos cicntíficos, a análise de transporte no turismo restringe-se aos aspectos históricos do conforto, da segurança, da freqüência e da regularidade. Confunde-se com o transporte geral,

1 Engenheiro e Pós-(iraduado cm (omércio Exicrior. Prolessur de Transportes na Faculdade de Turisno) de Santos.

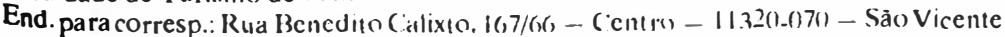
- SP - Brasil. 
diferenciando-se somente quanto dis normas legatis a serem oberervaclas e às cláusulas dos contratos de fretamento éou arrondiamento, peculiares aos próprios serviços I urísticus.

Pode-se dizer que náo há lurisno sem transporte e que a pripria definição de turista engloba, obrigatoriamente, o deslocamento de um lugar para outro. () transporte, em termos amplos, envolve uma mudança de local, no espaço, que se pode produzir ou náo, sem a alıeraçâo de seus aspectos essenciais de segurança é confortor.

No consumo do tempo ambos, transporte e turismo, atcndem múltiplas funçōes para o mesmo objetivo e, devido ato scu profundo inter-re lacionamento, requerem estudos específicos, que resultem ultrapassar situações comuns, tais como: distintos tratamentos fïscais, distintos regimes de financiamento, distintos regimes trabalhistas e diferentes mıdos de gestão.

Portanto, este breve relato é uma tentativa de situar o Turismo dentro da problemática geral do Transporıce, através da análise imediata dos custos inerentes à atividade turística, ou scja, transporte c cstada.

\section{DESENVOLVIMENT() DOS TRANSPORTES E SUAA FUNÇÃO ECONOMICA}

O revolucionário desenvolvimento dos transportes dá o "sentimento" econômico da relaçáo entre a imobilidade c a pobręat, verificadia em todos os países visitados. Nas viagens internacionatis podc-se constatar as discrepâncias entre os níveis de vida, produçāo é consumo das naçōes visitadas, ricas ou pobres.

Para um plancjador, qualquer que scja a sua áréa de aluaçáo, o transporte deverá considerar os seguintes axiomas:

a) tempo e energia sảo desperdiçados sc nào plancjados c náo operados adequadamente;

b) investimento inadequado $\mathrm{cm}$ transporte reduz a cficiência de investimentos em outros sctores.

Sob essas condiçōes, a habilidade de vender o produto turístico em mercados mundiais scrá facilitada.

No turismo nacional c internacional, obscrva-sc que nem scmpre é a falta total de transporte, mas a inscgurança, o alto custo, os horários lentos e os altos índices de danos e furtos que encarecem as viagens. Se esses obstáculos nāo forcm ult rapassados haverá uma restriçāo do iner- cado, aumento do custo de produçāo e preços acima do alcance dos consumidores, perdendo-se as vantagens potenciais de uma localidade ou regiāo.

Um outro ponto importante a ressaltar é quc os transportes são condiçōes necessánias, porém, não suficientes para o desenvolvimento econômico de qualquer atividade e, especialmente, do turismo. Fica claro, todavia, através de amostras relativas ao tráfego e aos níveis de renda, que o volume das operaçiess de transporte está intimamente relacionado com o progresso cconômico. ()nde a cconomia de uma nação está subdesenvolvida também haverá um baixo volume de transporte onde o transporte é reduzido, o sistema econômico é retardado. Assim, a questão a ser respondida não é sc o transporté é importante ou mais importante que outro fator, mas saber, precisamente, ‘'m quec circuıısitâncias e bases toma-se crílica a sua disponibilidade.

Em termos mundiais, a questáo básica é como at ingir os dois terços do mundo que permanecem inalcançados pelos transportes, a fim de alcançar uma "resoluçào" cconòmica do turismo.

\section{TÉCNICAS DE ANÁLISE DOS TRANSPORTES E PLANIFICAÇÃO DO TURISM()}

Na planificação do turismo, é importante que scjam utilizados instrumentos clássicos de análise de transportes, tais como a visão analí tica por eixos cartesianos c o estudo em linhas de isocustos. Pclo primeiro detecta-se a principal "prática de lıurismo" da localidade cstudada, enquanto pelo segundo verifica-sc qual a açāo a scr tomada. Portanto, cssas duas técnicas, quando aplicadas num mesmo estudo de custo do transporte e da estada, podem oferecer subsídios à planificação do turismo em um determinado núcleo receptor, como se analisa a seguir.

\subsection{Visão Analítica por Eixos Cartesianos}

Por hipótese ć possível delincarem-se contornos das diferentes práticas de turismo, distribuindo-as cartesianamente quanto aos componentes essenciais do custo de transporte e estada, conforme mostra a Figura 1 (p. 86)

Analisando os dados dessa figura, observa-se que os componentes constitutivos do produto turístico adquirem, segundo a classe, uma peculiar significação. Excmplificando, pode-se notar no tııismo religioso um pequeno custo de estada c um médio custo de transporte, como ocorre nas romarias aos locais de interesse religioso. De outro lado, o turismo 


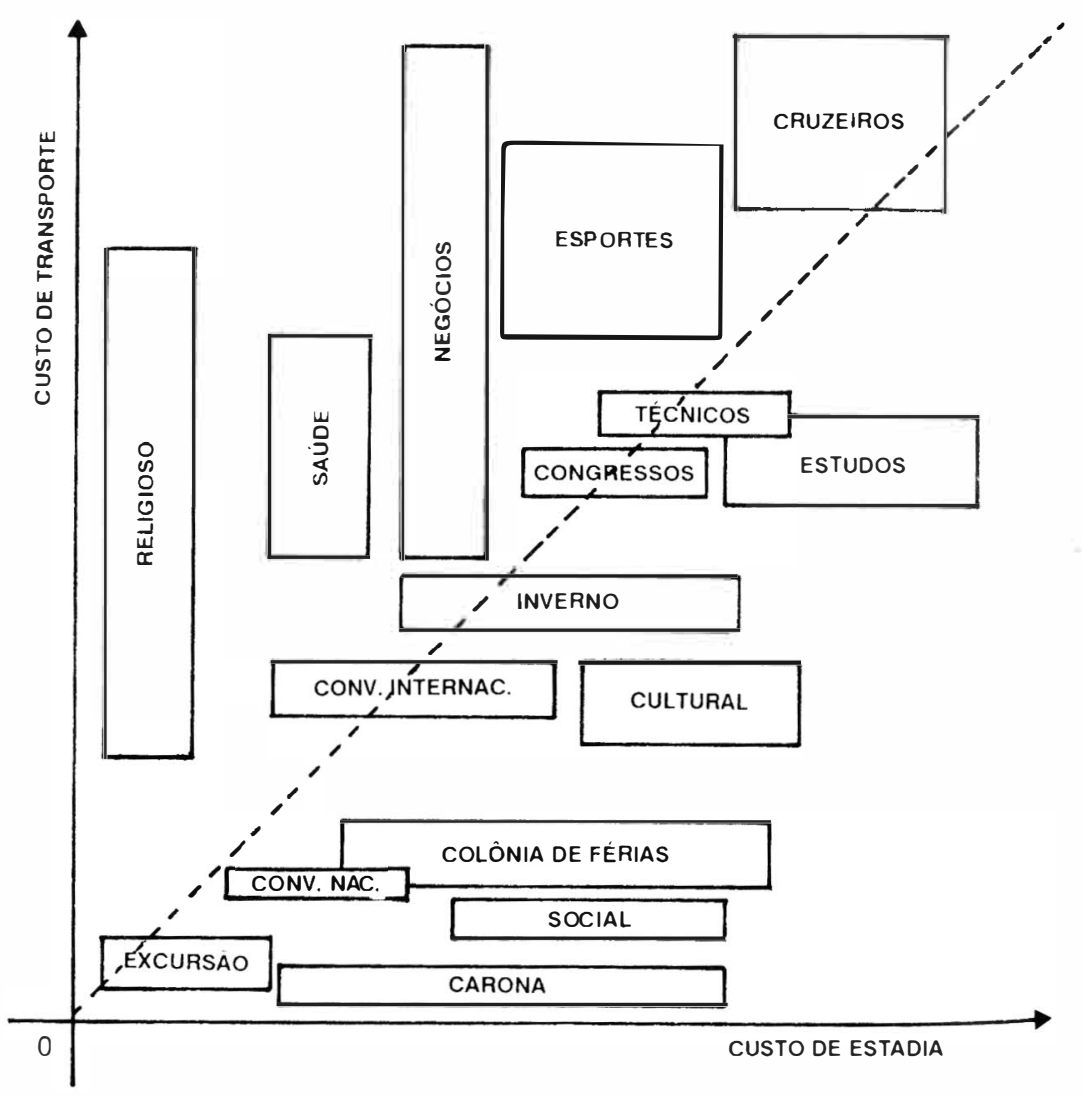

FIGURA 1 - Sistema de Eixos Cartesianos com os contornos das Variaçōes de "Práticas de Turismo" realizado na modalidade de "carona" tem baixo custo de transporte e médio custo de estada. No extremo estão os crizeiros marítimos, como responsáveis pelo maior custo de cstada c transporte, pois acontecem concomitantemente. Nos demais, os custos de iransportes ultrapassam os custos de estada ou vice-versa. Ainda nessa figura aparece uma linha de $45^{\circ}$, com a finalidade de se avaliar o conjunto das "práticas de turismo" que se situa acima ou abaixo da mesma, indicando se o gasto total do turismo é provocado predominantemente pelo transportc ou pela estada.

Deve-se considerar, entretanto, que a linha de tendências dos custos de transportes c dos custos de estada não variam de forma idêntica. Os transportes, provavelmente, não delincarão um aumento de custos tão exponencial quanto os de hospedagem. Nesta, os aumentos do custo da construção pela especulação imobiliária, dos matcriais, dos equipamen-

tos e a grande porcentagem de mão-de-obra necessária ao cmpreendimento hoteleiro fazcm crescer os custos de forma substancial. Com a oferta tecnológica, de estrutura de custos diametralmente diferente, o transporte apresenta um barateamento cm relação à estada, e indica tendência do desenvolvimento do turismo de maior percurso.

Neste sentido, deve-se considerar o tempo disponível no turismo itinerante ou no sedentário, na sazonalidade ou fora dela, influenciando a demanda por transporte c hospedagem de forma crescente. Como obstácalo, os custos poderão afetar as duas atividades.

Um segundo passo no estudo do custo de transporte cestadia pode definir uma situação de geração e at ração de viagens, como se vê no item a seguir.

\section{Estudos em Linhas de Isocustos ${ }^{2}$}

Apontadas duas cidades centro de gravidade de uma região, poderse-á desenhar pares de linhas de isocustos determinadas, analiticamente, como produto do custo de estada pelo de transporte. Esses custos tratados adequadamentc por catcgoria de hospedagem e por quilômetro percorrido, nos diferentes meios de transportes, quando gravados em escala conveniente, identificarão zonas de influĉncia econômica cm atraçāo ou geração de viagens. Havendo cruzamento dessas "famílias" de curvas, define-se uma outra linha, a de "indiferença". Recebe esta denominação pois será indiferente às pessoas que, localizadas nas proximida-

2 O termo isocustos ć um neologismo tomado por scmelliança uc isóbaras. isócronas, isotermas etc. Neste artigo ć entendido como mestmen cusste. 
des dela, se desloquem para uma ou outra cidiale, considerados essen. cialmente os custos desses transportc e hospedagem. ${ }^{3}$

Na Figura 2, verifica-se que, para sc accssar duas capitais brasileiras, como São Paulo e Salvador, haverá um custo de transporte e um custo de hospedagem. Tais custos identificarāo zonas de influência para atração de viagens turísticas, e justificarão a escolha de um ou outro destino turístico. Por exemplo, se uma dessas duas cidades proporcionar redução de custos e, conseqüentemente de preços no transporte ou na hospedagem, através de incentivos c/ou benefícios fiscais, promoverá o deslocamento de turistas em sua direção.

Assim, pode-se definir quais as áreas potencialmente favoráveis e potencialmente adversas à veiculaçāo da mensagem turística; quais as açōes políticas a serem desencadeadas no scgmento de transporte e hospedagem para a atraçāo de um maior número de turistas; quais os incentivos a serem priorizados; quais os melhoramentos a serem executados.

Como tese de estudo, deve-sc ainda agregar a hipótese de haverem cidades "alternativas" nas regiōes estudadas. Essas cidades poderāo provocar, conforme seu potencial (positivo ou negativo), uma deformaçāo das linhas de isocustos c uma flexāo na linha de indiferença, deslocando esta última para regiōes distantes do pólo estudado (Figura 3, p. 90).

A existência de cidades relativamente próximas, como é o caso de Belo Horizonte e Cidades Históricas entre Sào Paulo e Salvador, induzirá a possiblidade de viagens "casadas" com algumas cidades minciras, alterando a relatividade de custos de transportes e hospedagem, c atraindo mais turistas, mesmo que somente uma delas promova uma reduçáo de custos.

\section{CONCLUSÃO}

Muito mais que uma simples análise de cust os relativos a transporte e hospedagem, de natureza eminentemente econômica, o cstudo apresentado por eixos cartesianos c linhas de isocustos é um importante instrumental político e indicador potencial das açōes a serem implementadas, nos locais em que o Turismo é conduzido com seriedade. A única inconveniência a assinalar é a forma trabalhosa que impõe, scmpre analisando os casos dois a dois, e exigindo esforço, aplicaçāo e aptidảo à "paciência".

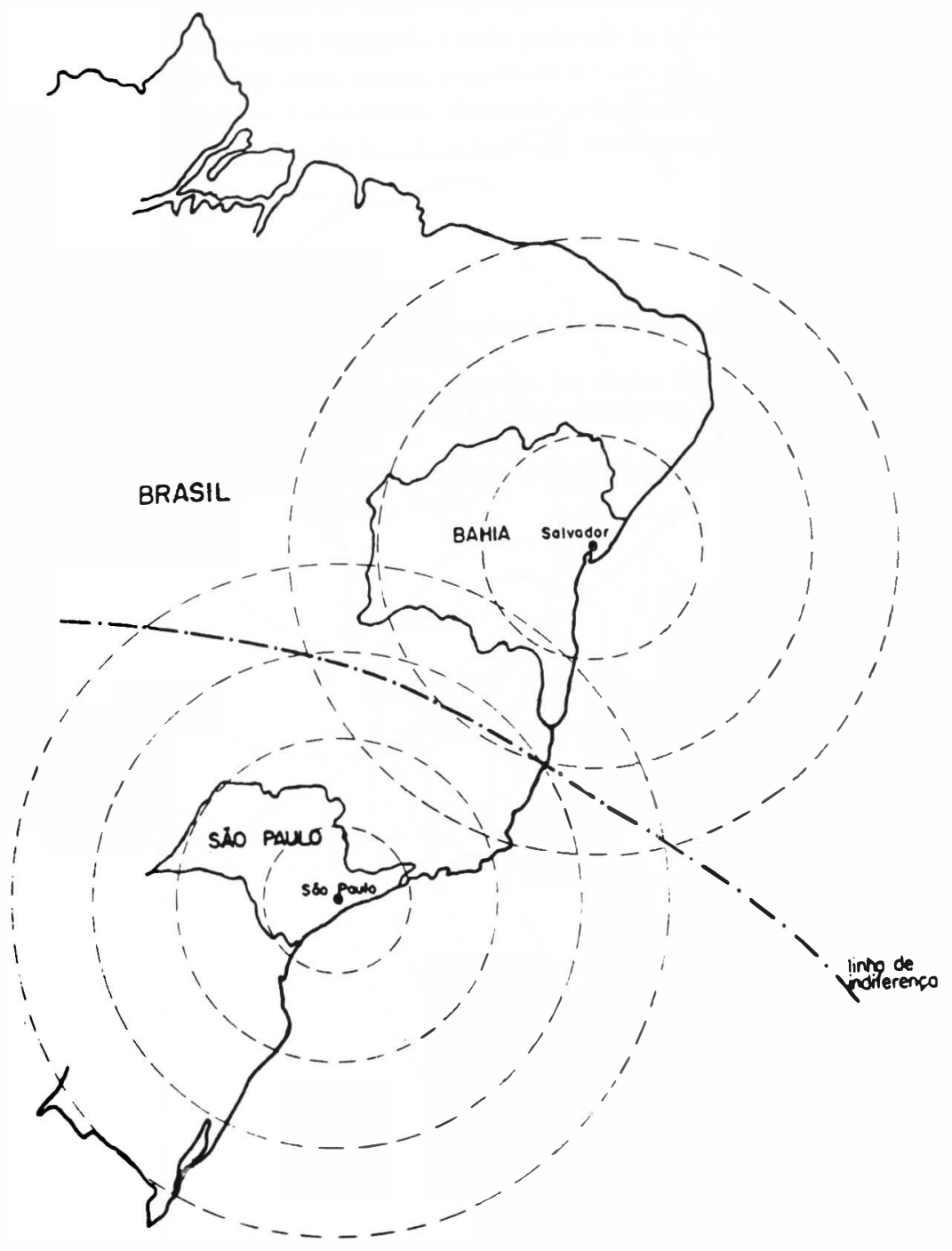

FIGURA 2 - Linhas de Isocustos a partir de São Paulo e Salvador 


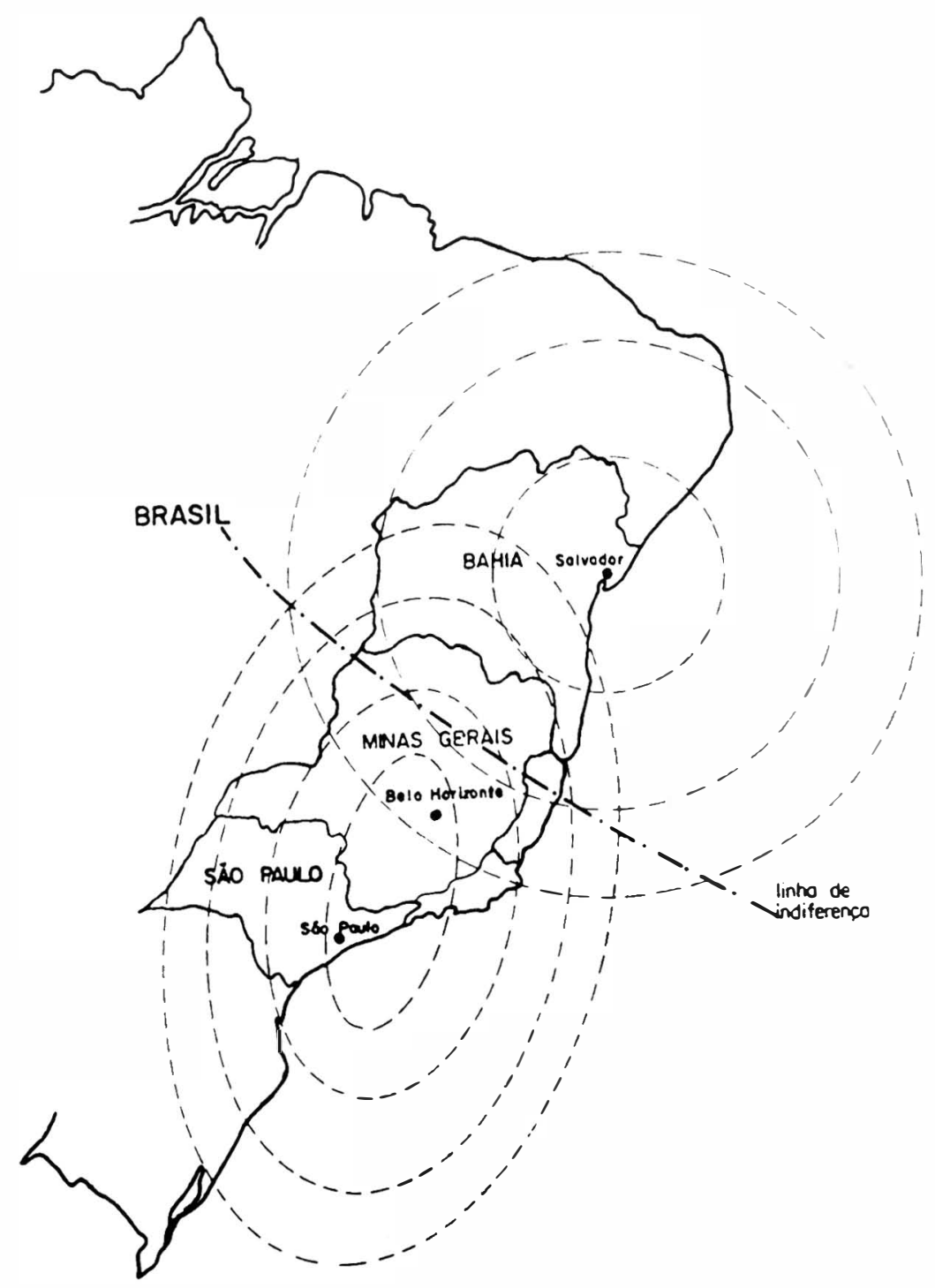

FIGURA 3 - Linhas de Isocustos a partir de Săo Paulo e Salvador, influenciadas pela proximidade de Belo Horizonte e Cidades Históricas
Ainda que carente de uma completa análise cconômica, motivo pelo qual o Turismo é sempre relegado a uma prioridade postcrior, esse estudo demonstra, aos dirigentes locais, estaduais e federais, uma visualização de critérios objetivos e concretos, deixando o fenômeno social/cultural e as belezas naturais de cada localidade como atrativos complementares.

\section{BIBLIOGRAFLA}

COLÉGIO OFICIAL DE ENG. DE ESTRADAS, CANAIS E PORTOS. 1974. Curso de engenharia de transportes. Madrid: Edix.

MELO, Jase C. 1975. Plancjamento dos transportes. Sao Paulo: Mac Ciraw-Hill do Brasil.

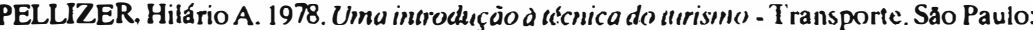
Pioneira.

OWEN, Wilfred. 1975. Estratcgia para os transportcs. Săo Paulo: Pioncira. 